\title{
Article
}

\section{An exploratory study into the effects of a 20 minute crushed ice application on knee joint position sense during a small knee bend.}

Alexander, Jill, Selfe, James, Oliver, Ben, Mee, Daniel, Carter, Alexandra, Scott, Michelle, Richards, Jim and May, Karen Alison

Available at http://clok.uclan.ac.uk/12033/

Alexander, Jill ORCID: 0000-0002-6492-1621, Selfe, James, Oliver, Ben ORCID: 0000-0003-4841-3309, Mee, Daniel, Carter, Alexandra, Scott, Michelle, Richards, Jim ORCID: 0000-0002-4004-3115 and May, Karen Alison ORCID: 0000-0001-9621-8466 (2016) An exploratory study into the effects of a 20 minute crushed ice application on knee joint position sense during a small knee bend. Physical Therapy in Sport, 18 . pp. 21-26. ISSN 1466-853X

It is advisable to refer to the publisher's version if you intend to cite from the work. http://dx.doi.org/10.1016/j.ptsp.2015.06.004

For more information about UCLan's research in this area go to http://www.uclan.ac.uk/researchgroups/ and search for <name of research Group>.

For information about Research generally at UCLan please go to http://www.uclan.ac.uk/research/

All outputs in CLoK are protected by Intellectual Property Rights law, including Copyright law. Copyright, IPR and Moral Rights for the works on this site are retained by the individual authors and/or other copyright owners. Terms and conditions for use of this material are defined in the policies page. 
An exploratory study into the effects of a 20 minute crushed ice application on knee joint position sense during a small knee bend.

\section{Objectives}

The effect of cryotherapy on joint positioning presents conflicting debates as to whether individuals are at an increased risk of injury when returning to play or activity immediately following cryotherapy application at the knee. The aim of this study was to investigate whether a 20 minute application of crushed ice at the knee immediately affects knee joint position sense during a small knee bend.

\section{Design}

Pre and post-intervention.

\section{Setting}

University movement analysis laboratory.

\section{Participants}

Eleven healthy male participants.

\section{Main Outcome Measures}

Kinematics of the knee were measured during a weight bearing functional task pre and post cryotherapy intervention using three-dimensional motion analysis (Qualisys Medical AB Gothenburg, Sweden). Tissue cooling was measured via a digital thermometer at the knee.

\section{Results}

Results demonstrated significant reductions in the ability to accurately replicate knee joint positioning in both sagittal $(P=.035)$ and coronal $(P=.011)$ planes during the descent phase of a small knee bend following cryotherapy.

\section{Conclusion}

In conclusion a twenty minute application of crushed ice to the knee has an adverse effect on knee joint repositioning. Team doctors, clinicians, therapists and athletes should consider these findings when deciding to return an athlete to functional weight bearing tasks immediately following ice application at the knee, due to the potential increase risk of injury. 


\section{Introduction}

The application of ice for the treatment of soft tissue injuries is common practice within sport and clinical settings (Bleakley, McDonough \& MacAuley, 2004; Costello \& Donnelly, 2011; Bleakley, Costello \& Glasgow, 2012). Cryotherapy in this instance is generally applied to provide cold induced analgesia by aiming to reduce tissue temperatures to $13.6^{\circ} \mathrm{C}$ (Bugaj,1975; Jutte, Merrick, Ingersol \& Edwards, 2001; Bleakley et al., 2012) in order for physiological changes to occur (Nadler, Weingand \& Kruse, 2004; Algafly \& George, 2007; Rice, McNair \& Dalbeth, 2009; Fishman, Ballantyne, Rathmell, \& Bonica, 2010; Knight \& Draper, 2013). It has been previously established that cellular metabolism is reduced by $10 \%$ when skin surface temperatures (Tsk) are between $10-11^{\circ} \mathrm{C}$ (Bugaj, 1975). Other research suggests a reduction in nerve conduction velocity (NVC) occurs at $12.5^{\circ} \mathrm{C}$ (Jutte et al., 2001), and hypometabolism onset at $15^{\circ} \mathrm{C}$ (Knight \& Draper, 2013). Algafly and George (2007) reported a 33\% reduction in nerve conduction velocity (NCV) when Tsk was cooled to $10^{\circ}$, supporting earlier work by Chesterton, Foster, \& Ross (2002). Kennet, Hardaker, Hobbs \& Selfe, (2007) suggests Tsk between $10^{\circ} \mathrm{C}-15^{\circ} \mathrm{C}$ can therefore define an optimum therapeutic Tsk range. It is interesting that although the effects of cryotherapy on proprioception and joint position sense (JPS) are largely unknown (Costello \& Donelly, 2010), clinicians and therapists continue to apply cold modalities such as ice in a clinical or pitch side setting (Bleakley et al., 2011). Anecdotal evidence suggests that ice is applied during rehabilitation to facilitate joint movement. Athletes therefore often perform exercises immediately after cryotherapy. There is however, little consensus in the literature on how functional performance and joint range of movement is affected by the application of cold, with recent systematic reviews (Bleakley et al., 2012; Bleakley \& Costello, 2013) reporting varying conclusions.

In sport poor JPS has been associated with functional instability and increased risk of knee injury thought to be caused by increases in postural sway, balance deterioration and disturbances to gait patterns (Kiran, Carlson, Medrano \& Smith, 2010). Although it is still undecided as to how JPS reduces due to cryotherapy applications and the implications it may have on the risk of injury, due to potential changes in functional stability. Assessment of joint position can influence clinical practice, with 
therapeutic interventions known to affect dynamic stability (Williams et al., 2001) it is recommended that active angle reproduction (AAR) should be used as a method of assessment for knee JPS (Selfe et al., 2006). Accuracy of the ability to reproduce a joint angle is affected by the type of test applied, during AAR quicker positional stabilization was accomplished compared to passive angle reproduction (PAR) (Selfe et al., 2006). The application of active reproduction tests in the current study closely mimics functional performance in athletes, supporting previous research (Stillman, 2002; Bennell et al., 2005).

The reliability of previous research around JPS and cryotherapy application is debatable; Surenkok et al (2008) found that knee JPS was negatively affected following both the application of a cold pad and post application of a cold spray using a passive knee repositioning test. Neither Tsk nor duration of cold pad or cold spray was reported. Thieme et al (1996) reported no significant difference in active movement reproductions following a 20 minute application of an ice pack to the knee compared to the control of no ice pack. The use of the most accurate trial instead of mean error in this study has been questioned as trials that produced a less accurate angle were disregarded (Costello \& Donnelly, 2010). Alternatively a recent systematic review by Bleakley et al (2012) suggested that a negative effect on functional performance occurs after 20 minute cryotherapy application. In addition, Ribeiro et al (2013) supports the recommendation that cryotherapy has a damaging effect on proprioception at the knee. Functional impairments in JPS at the knee were also reported by Watanabe et al (2013) following a cryotherapy application time of 15 minutes. Studies on the ankle (Hopper, Whittington \& Davis, 1997; La Riviere \& Osternig, 1994) and the shoulder (Wassinger, Myers, Gatti, Conley \& Lephart, 2007; Dover \& Powers, 2004) have also shown conflicting results. Reductions in JPS are commonly assessed clinically to identify proprioceptive deficits these may indicate that an individual is at risk of injury (Uchio et al. 2003; Bleakley, McDonough \& MacAuley, 2006; Zazulak, Hewett, Reeves, Goldberg \& Cholewicki, 2007; Wassinger et al. 2007; Surenkok et al., 2008; Costello \& Donnelly, 2010). It is supported by Whatman, Hume \& Hing (2013) that the SKB lower extremity functional test is a useful tool in clinical decision making concerning risk of injury and dynamic alignment of the lower limb. Literature fails to agree whether it is safe to return athletes to dynamic 
functional tasks immediately following the application of ice to the knee. This study therefore examines the effects of crushed ice application to the knee using a small knee bend (SKB) as a functional assessment to observe knee JPS.

\section{Methods}

\subsection{Participants}

This exploratory study included Eleven healthy male volunteers who regularly participate in team, land based sports took part in the study, with an average age of $21.3 \pm 1.7$ years, body mass of $83.5 \pm 32.5 \mathrm{Kg}$ and height of $182 \pm 12.8 \mathrm{~cm}$. All participants provided written consent to take part in the study. The study was conducted according to the Declaration of Helsinki (WMA, 2008) and approved by UCLan Built, Sport and Health Ethics Committee (BuSH 128). All male participation was chosen to increase sample homogeneity due to gender differences found in response to local cooling (Cankar \& Finderle, 2003). Criteria for exclusion from the study included previous knee joint surgery, lower limb injury in the last 6 months, referred pain either to or from the knee or any contraindications to cryotherapy (Kennet et al., 2007).

\subsection{Intervention Protocol}

The study was a single group, pre-test-post-test design. The testing protocol took place in a movement analysis laboratory. Kinematic data were collected pre and post intervention using a ten camera infra-red Oqus motion analysis system (Qualisys medical $A B$, Gothenburg, Sweden) collecting at $115 \mathrm{~Hz}$. Cameras were arranged in an umbrella formation (Richards, 2008). Participants acclimatised to a steady thermal state for a 15 minute period, prior to intervention; during this phase passive retro-reflective markers were placed on the following anatomical landmarks (Figure 1); posterior superior iliac spine (PSIS), anterior superior iliac spine (ASIS), greater trochanter, medial and lateral epicondyle of the femur, medial and lateral malleolus, calcaneus, dorsal aspect of first and fifth metatarsal heads and the middle cuneiform, acromion, lateral epicondyle of the humerus and radial styloids. Clusters of four markers mounted on a thin sheath of lightweight carbon fibre were applied to the anterolateral aspect of the femur and tibia. Three measures of Tsk were taken from the 
centre of participants' patella following the acclimatisation period, using a digital thermometer (Fora, Gallen, Switzerland IR19). The accuracy of the skin surface thermometer meets the accuracy required in ASTM E1965-98 and the EC directive 93/42/EEC.

Pre testing, familiarisation to the SKB protocol of $45^{\circ}$ was conducted measured by a goniometer, prior to kinematic data collection. The participant was given three attempts to replicate the $45^{\circ} \mathrm{SKB}$ in order to familiarise themselves with the movement pattern (Reurink et al., 2013). Following the 'practice' attempts participants then completed five SKB using three dimensional (3D) motion analyses to measure knee motion. No white noise or blindfolds were worn by the participants; it was felt that by removing sensory cues the eco-validity of the study would be inhibited, an athlete returning to sport immediately following the application of ice would not usually have sensory cues removed. The methodology in the current study uses an active target angle of $45^{\circ}$. This supports similar research by Olsson et al., (2004) that suggests knee JPS test angles should be between $40^{\circ}-80^{\circ}$ flexion when assessing SKB. Each repetition of the SKB was held at a target angle of $45^{\circ}$ for 5 seconds. Literature supports a five second hold (Olsson et al., 2004; Mohammadi et al., 2008; Costello, Algar \& Donelly, 2012), suggesting that this allows for awareness of limb position (Costello \& Donnelly, 2011). Testing was carried out on the participant's non-dominant leg, shown to be the most likely for knee injury to occur, in contact and non-contact sports (Vauhnik et al., 2008; Krajnc et al., 2010 and Ruedl et al., 2012). The dominant leg was determined by which leg they would normally kick a ball with to ensure the non-dominant leg was established (Surenkok et al., 2008).

Figure 1. Anatomical landmarks for marker placement, (a) anterior and (b) posterior.

Two anatomical markers were removed from the medial and lateral epicondyles of the knee prior to $800 \mathrm{~g}$ of crushed ice contained in a clear plastic bag applied over the anterior aspect of the nondominant knee. The aim of this application was to achieve a Tsk of between $10-15^{\circ} \mathrm{C}$. The bag of ice was covered by a damp single microfiber towel held in place by cling film wrap, for the clinically relevant time of 20 minutes (Owens, Hart, Donofrio, Haralabous \& Miezejewski, 2004; Kennet et al., 2007; Janwantanakul, 2009). Immediately post ice intervention three further Tsk measurements were taken, whilst the two anatomical markers on the knee were placed in the exact same position prior to 
the intervention. Marker points were highlighted previously on the participant's skin with washable pen pre-intervention so that marker replacement would be accurate. Collection of Tsk took approx. 8 seconds; participants then immediately produced the same SKB procedure, without any practice trials, followed by three further Tsk measurements.

\subsection{Analysis}

Maximum knee angle, minimum knee angle and knee joint range of motion (ROM) in all three planes of motion for both the loading (eccentric) phase of the movement and the entire (eccentric, hold and concentric) movement were measured. Data were processed in Qualisys Track Manager and then exported as C3D files to Visual3D (CMotion Inc., USA) software in order to quantify kinematic parameters, smoothed with a low pass Butterworth $6 \mathrm{~Hz}$ filter, allowing recognition of significant events within the data creating a report. All data was averaged within subjects prior to statistical analysis. The distribution of the data was assessed for normality using the Shapiro-Wilk test and found to be suitable for parametric statistical testing. A paired t-test was used to compare pre and post intervention data, with a Bonferroni correction applied, including data analysed using absolute error $(A E)$ for knee flexion. Statistical significance was set at $P<.05$. All statistical analysis was conducted using SPSS version 21.0 (SPSS, Inc., Chicago, USA).

\section{Results}

Results demonstrated significant changes in both the sagittal and coronal planes during the descent phase of the SKB. A significant decrease $(P=.035)$ in knee flexion in the sagittal plane demonstrated an angular difference of $-4.0^{\circ} \pm 5.4,95 \% \mathrm{Cl}\left(0.3-7.6^{\circ}\right)$, when comparing pre and post ROM (Fig. 2). A significant reduction in $A E(P=.002)$ post cryotherapy intervention in knee flexion was found. $A$ significant increase $(P=.011)$ toward a valgus shift occurred in the coronal plane post intervention (Table 3). No significant changes were found in knee joint velocity $(P=.579)$. Tsk demonstrated a significant reduction post cryotherapy intervention $(P=.001)$. Immediately post cryotherapy application average Tsk was recorded at $13.4^{\circ} \mathrm{C} \pm 2.9$, reflecting a skin temperature response to within the desired therapeutic range. 
Figure 2. Knee joint flexion during of a small knee bend in the sagittal plane, pre and post twenty minutes crushed ice application to the anterior aspect of the knee. *demonstrates a significant decrease in joint angular ROM post ice intervention in the sagittal plane.

Table 1. Knee joint ROM, varus-valgus during a small knee bend in the coronal plane, pre and post 20 minutes crushed ice application to the anterior aspect of the knee. *demonstrates a significant increase in valgus shift (joint angular ROM) post ice intervention in the coronal plane.

\section{Discussion}

Many athletes are required to return to functional activities following the application of cryotherapy treatments to meet performance pressures or as part of a targeted rehabilitative setting. Despite concerns regarding neuromuscular function following cryotherapy interventions, literature is vague as to how JPS is affected, immediately post cryotherapy application. The study's findings demonstrate a significant change $(P=.035)$ in the ability to reproduce knee joint flexion in the sagittal plane and a significant lack of varus control $(P=.011)$ with a subsequent valgus shift in the coronal plane, during the eccentric loading phase of the SKB, in line with previous research (Ribeiro et al., 2013; Watanabe et al., 2013; Uchio et al., 2003; and Surenkok et al., 2008). Analysis revealed no significant changes in the angular velocity of this movement. As expected, a significant decrease $(P=.001)$ in Tsk to within the desired therapeutic range was achieved, averaging $13.4^{\circ} \mathrm{C}$ immediately post crushed ice intervention, supporting previous research by Bleakley et al (2011).

\subsection{Pre/Post Knee Joint Flexion during SKB}

This is the first experimental study of its kind to our knowledge that assesses knee joint motion in all three planes using 3D motion analysis during a functional closed chain weight bearing assessment following ice intervention. This study's findings suggest knee JPS and control during the eccentric phase of the SKB was significantly altered after crushed ice applied to the anterior aspect of the knee. Findings support previous methods of measuring knee JPS during a SKB by using an active target angle of $45^{\circ}$, thus meeting the range of ideal test angle of between $40-80^{\circ}$ proposed by Olsson et al., (2004). Average pre intervention angle for all participants during the SKB was $49.1^{\circ} \pm 15.0$, with an average post intervention angle of $45.1^{\circ} \pm 13.7$. The angular decrease in the ability to accurately perform and repeat a similar knee joint flexion angle immediately following cryotherapy in this study by $4.0^{\circ} \pm 5.4$ (Figure 2) contradicts earlier studies by Costello \& Donnelly (2011) and Hart et al (2005). The current findings however support a suggestion by Uchio et al (2003) that the knee joint may become stiffer following cryotherapy application or sensitivity of JPS may decline resulting in 
reductions in knee flexion angles. This may be a reason for the inability to replicate participant's pre intervention angle of $49.1^{\circ} \pm 15.0$ but replicated an angle closer to the target angle of $45^{\circ}$, in the current study. AE data in knee flexion JPS supports this reduction in knee flexion angle post cryotherapy intervention $(P=.002)$.

Although the functional weight bearing close kinetic chain assessment used in the current study is likely to be the reason for the significant differences $(P=.035)$; often it is the non-dominant limb used to weight bear during functional tasks in sport, such as kicking a ball for example. JPS in the current study was measured on the participant's non-dominant limb during a dynamic SKB to measure changes in functional stability, in order to replicate a functional task relevant within sport. This may be another reason for the significant results in comparison to previous research. Furthermore, methods utilised by Costello and Donnelly (2011), allowed participants to use their hand for balance on a table, providing an outlet for sensory feedback therefore reducing any variations in postural sway. In another comparative study a 30 second rest period was included between post cryotherapy trials (Hart et al., 2005), therefore allowing for increases in NCV and peripheral mechanoreceptor efficiency (Algafly \& George 2007; Schepers \& Ringkamp 2010 and Herrera, Sandoval, Camargo \& Salvini, 2011), due to the rewarming effects that may have taken place. In the current study, participants immediately post 20 minutes of cryotherapy intervention performed the functional SKB assessment, therefore reducing the chance of gaining greater proprioceptive feedback prior to the SKB through rewarming. In support of Schepers \& Ringkamp (2010), we assume the slow adapting mechanoreceptors reduced their discharge rate under the effects of the cryotherapy intervention; therefore the disruption to the function of mechanoreceptors affected JPS in this study. Further investigation however, is still necessary to determine the actual mechanisms behind mechanoreceptor response under the conditions of cryotherapy.

Findings in the current study revealed a mean valgus shift of the knee joint of $1.0^{\circ}$ post cryotherapy intervention (Table 1). Therefore the ability to control joint stability decreased through the medial structures of the knee. Valgus translation of $1.0^{\circ}$ may seem minor, however as a percentage value this equates to an $18.2 \%$ valgus shift in relation to pre-loading varus movement. Consideration must be taken from this large percentile difference, which combined with flexion, excessive strain may be 
placed on knee structures, such as the anterior cruciate ligament (ACL), therefore the risk of sustaining an injury is potentially increased (Malinzak, Colby, Kirkendall, Yu \& Garrett, 2001; Ford, Myer \& Hewett, 2003; Hewett et al., 2005).

It is common practice within contact sports for athletes to continue competing following a short duration cryotherapy application to the lower limb. During sport, intermittent breaks in play are a common time when cryotherapy is provided to minimise pain (Bleakley et al., 2012). A systematic review by Bleakley et al (2012), suggested an application time of $<20$ minutes to minimise the potential for reduced performance outcomes immediately following ice application. This leads to questioning however, around achieving a desired therapeutic cooling range for the rationale of applying cryotherapy in the first place. Depending on the preferred clinical therapeutic effect, duration of cryotherapy application may differ, in support of Bleakley et al (2011) one method of icing may not be equally effective, as varied magnitudes and depths of critical cooling would occur. Findings in the current study support the recommendation by Bleakley et al (2012) that athletes may be at a performance disadvantage but also in addition suggests a potential increase risk of injury by an athlete performing functional movements immediately after 20 minutes of cryotherapy application at the knee. This study investigates the changes in JPS immediately after cryotherapy; in support of recent study by Ribeiro et al (2013) it would be useful to observe the time it takes to return to pre intervention baseline measures in future studies following cryotherapy application using the same methods.

The specific mechanism through which cryotherapy altered knee joint control could not be determined by this study. It can be postulated however, that physiological variations occurred causing adverse adaptations to knee joint mechanics. These changes could be due to one or a combination of these factors; altered NCV as indicated by Jutte et al (2001), where NCV is found to be reduced at $12.5^{\circ} \mathrm{C}$ in line with temperatures recorded in the current study, altered spindle muscle activity, reductions in muscle strength or altered sensory information from superficial mechanoreceptors. The application of crushed ice over the lateral aspect of the knee may have affected neuromuscular control. Due to the superficial anatomical arrangement of the lateral femoral cutaneous nerve (Palastanga \& Somes 2012) it is proposed that ice application penetrated this superficial nerve more easily than the distribution of nerves over the deeper medial aspect of the knee. The current study support the 
concept of changes in proprioceptive feedback through altered mechanoreceptor mechanisms due to cryotherapy application, reported previously by Schepers and Ringkamp (2010). Previous studies, particularly at the knee, support the suggestion that sensory feedback via receptors in the skin have an importance in proprioceptive feedback (Richards \& Selfe 2012). Cryotherapy has been found to reduce NCV in sensory nerves greater than motor nerves (Herrera et al., 2011). It was previously thought that cutaneous receptors have not played a part in joint stability; the current study however proposes a greater consideration should be taken into the relevance of sensory feedback via the skin, and its involvement in proprioceptive feedback for JPS (Richards \& Selfe 2012). The explanation of a reduction in muscle strength due to cryotherapy application may be supported by the findings in the current study. Although muscle strength was not measured it could be assumed that alteration of Tsk and muscle temperature occurred. Original work by Sargeant (1987) noted reductions in peak force, power and maximal mean power in muscles following the reduction of muscle temperature from cold water immersion. In agreement a recent review of current evidence by Bleakley et al (2012) suggests that cooling reduces muscle strength. A reduction in muscle strength due to cryotherapy may impact the ability of the lower limb musculature to stabilise the joint during functional tasks. This may have been a further reason behind the reductions in knee joint control reported in the current study.

\section{Conclusion}

The current study supports the suggestion that significant changes of JPS occur at the knee immediately following the application of crushed ice cryotherapy. Therefore team doctors, clinicians, therapists and athletes should be aware of the potential increase risk of injury to the ACL and or medial complex during closed chain weight bearing activities immediately following 20 minutes of crushed ice cryotherapy application to the knee due to changes in eccentric control. Future research is needed to establish the effects of cryotherapy application alongside the specific mechanisms behind the changes in knee joint control.

\section{References}

1. Algafly, AA and George KP. (2007). The effect of cryotherapy on nerve conduction velocity, pain threshold, and pain tolerance. Br J Sports Med, 41, 365-369. 
2. Bennell K, Wee E, Crossley K, et al. (2005). Effects of experimentally-induced anterior knee pain on knee joint position sense in healthy individuals. J Orthop Res, 23, 46-53.

3. Bleakley C, McDonough S and MacAuley, D. (2004). The use of ice in the treatment of acute soft-tissue injury: a systematic review of randomized controlled trials. Am J Sports Med, 32, 251-261.

4. Bleakley C, McDonough S and MacAuley, D. (2006). Cryotherapy for acute ankle sprains: a randomised controlled study of two different icing protocols. Br J Sports Med, 40, 700-705.

5. Bleakley C, Glasgow, P, Phillps, N, Hanna, L, Callaghan, M, Davison, G, Hopkins, T and Delahunt, E. (2011). Management of acute soft tissue injury using protection, rest, ice, compression and elevation recommendations from the Association of Chartered Physiotherapists in Sports and Exercise Medicine (ACPSM). Physio's in Sport, 1, 1-22.

6. Bleakley C, Costello JT, Glasgow PD. (2012). Should athletes return to sport after applying ice. A systematic review of the effect of local cooling on functional performance. Sports Med, 42, 69-87.

7. Bleakley C and Costello JT. (2013). Do thermal agents affect range of movement and mechanical properties in soft tissues? A systematic review. Arch Phys Med Rehabi, 94, 149163.

8. Bugaj R. (1975). The cooling, analgesic, and rewarming effects of ice massage on localized skin. Phys Ther, 55, 11-19.

9. Cankar, K and Finderle Z. (2003). Gender differences in cutaneous vascular and autonomic nervous response to local cooling. Clin Autonomic Res, 13, 214-220.

10. Chesterton, L, Foster, N and Ross, L. (2002). Skin temperature response to cryotherapy. Arch Phys Med and Rehab, 83, 543-549.

11. Costello JT, Algar, LA and Donnelly AE. (2012). Effects of whole-body cryotherapy $\left(-110^{\circ} \mathrm{C}\right)$ on proprioception and indices of muscle damage. Scand J Med Sci Sport, 22, 190-198.

12. Costello JT and Donnelly AE. (2010). Cryotherapy and joint position sense in healthy participants: A systematic review. J Athl Train, 45, 306-316. 
13. Costello JT and Donnelly AE. (2011). Effects of cold water immersion on knee joint position sense in healthy volunteers. J Sports Sci, 2011, 29, 449-456.

14. Dover G, Powers ME. (2004). Cryotherapy does not impair shoulder joint position sense. Arch Phys Med Rehabil, 85, 1241-1246.

15. Fishman, SM, Ballantyne JC, Rathmell, JP and Bonica, JJ. Bonica's management of pain. (2010) $4^{\text {th }}$ Ed. Baltimore: Lippincott, Williams and Wilkens. P1347-1348.

16. Ford, KR, Myer, GD and Hewett, TE. (2003). Valgus knee motion during landing in high school female and male basketball players. Med \& Sci Sports \& Ex, 35, 1745-1750.

17. Hart JM, Leonard JL, Ingersoll CD. (2005). Single-leg landing strategy after knee joint cryotherapy. J Sport Rehabil, 14, 313-320.

18. Herrera, E, Sandoval, MC, Camargo, DM, and Salvini, TF. (2011) Effect of walking and resting after three cryotherapy modalities on the recovery of sensory and motor nerve conduction velocity in healthy subjects. Brz J Phys Ther, 15, 233-240.

19. Hewett, TE, Myer, GD, Ford, KR, Heidt, RS, Colosimo, AJ, McLean, SG, Van den Bogert, AJ, Paterno, MV, and Succop, P. (2005). Biomechanical measures of neuromuscular control and valgus loading of the knee predict anterior cruciate ligament injury risk in female athletes. A prospective study. Am J Sports Med, 33, 492-501.

20. Hopper D, Whittington D, Davis J. (1997). Does ice immersion influence ankle joint position sense? Physiother Res Int, 2, 223-236.

21. Janwantanakul, P. (2009). The effect of quantity of ice and size of contact area on icepack/skin interface temperature. Physio, 95, 120-5.

22. Jutte LS, Merrick MA, Ingersoll CD, Edwards JE. (2001). The relationship between intramuscular temperature, skin temperature, and adipose thickness during cryotherapy and rewarming. Arch Phys Med Rehabil, 82, 845-850.

23. Kennett, J, Hardaker, N, Hobbs, S and Selfe J. (2007). Cooling efficiency of 4 common cryotherapeutic agents. J Athl Train, 42, 343-348.

24. Kiran, D, Carlson, M, Medrano, D and Smith, D. (2010) Correlation of three different knee joint position sense measures. Phys Ther Sport, 11, 81-85. 
25. Knight, KL and Draper, DO. (2013) Therapeutic Modalities. The Art and Science. $2^{\text {nd }}$ Ed. Baltimore: Lipincott, Williams and Wilkens. p214-217.

26. Krajnc, Z, Vogrin, M, Recnik, G, Crnjac, A, Drobnic, M and Antolic, V. (2010). Increased risk of knee injuries and osteoarthritis in the non-dominant leg of former professional football players. Middle Eur J Med, 122, 40-43.

27. La Riviere J, Osternig L. (1994). The effect of ice immersion on joint position sense. J Sport Rehabil, 3, 8-11.

28. Malinzak, RA, Colby, SM, Kirkendall, DT, Yu, B and Garrett, WE. (2001). A comparison of knee joint motion patterns between men and women in selected athletic tasks. Clin Biomech, $16,438-445$

29. Mohammadi, FS, Taghizadeh, F, Ghaffarinejad, M, Khorrami and Sobhani, S. (2008). Proprioception, dynamic balance and maximal quadriceps strength in females with knee osteoarthritis and normal control subjects. Int J Rheum Disease, 11, 39-44.

30. Nadler, SF, Weingand, K and Kruse, RJ. (2004). The physiologic basis and clinical applications of cryotherapy and thermotherapy for the pain practitioner. Pain Physician, 7, 395-399.

31. Olsson, LH, Lund, M, Henrikson, H, Rogind, H, Biddal and Danneskoid-Samsoe, B. (2004). Test-retest reliability of a knee joint position sense measurement in sitting and prone position. Adv Physio, 6, 37-47.

32. Owens, E, Hart, J, Donofrio, J, Haralabous, J, and Miezejewski, E. (2004). Paraspinal skin temperature patterns: an interexaminer and intraexaminer reliability study. J Man Physiol Ther, 27, 155-59.

33. Palastanga, N and Soames, R. (2012). Anatomy and Human Movement Structure and Function. $6^{\text {th }}$ Ed. Edinburgh: Churchill Livingstone Elsevier. p317-318.

34. Reurink, G, Goudswaard, G, Oomen, H, Moen, M, Tol, J, Verhaar, J, and Weir, A. (2013). Reliability of the active and passive knee extension test in acute hamstring injuries. $\mathrm{Am} \mathrm{J}$ Sports Med, 41, 1757-61. 
35. Rice, D, McNair, PJ and Dalbeth, N. (2009). Effects of cryotherapy on arthrogenic muscle inhibition using an experimental model of knee swelling. Arth \& Rheum, 61, 78-83.

36. Richards, J. (2008) Biomechanics in Clinical Research. Edinburgh: Churchill Livingstone. P107-12.

37. Richards J and Selfe J. Clinical principles of kinesiology. In, Sivananthan, S; Sherry, E; Warnke, $\mathrm{P}$ and Miller, M. Mercer's Textbook of Orthopaedics and Trauma. Tenth Edition. 2012: 214-215.

38. Ruedl, G, Webhofer, M, Helle, K, Strobl, K, Shranz, A, Fink, C, Gatterer, H, and Burtscher, M. (2012). Leg dominance is a risk factor for non-contact anterior cruciate ligament injuries in female recreational skiers. Am J Sports Med, 40, 1269-1273.

39. Sargeant, AJ. (1987). Effect of muscle temperature on leg extension force and short-term power output in humans. Eur J Appl Physiol, 56, 693-698.

40. Schepers, RJ and Ringkamp M. (2010). Thermoreceptors and thermosensitive afferents. Neurosci Biobehav Rev, 34, 177-184.

41. Selfe J, Callaghan, M, McHenry, A et al. (2006). An investigation into the effect of number of trials during proprioceptive testing in patients with patellofemoral pain syndrome. $\mathrm{J}$ Orthop Res, 24, 1218-24.

42. Stillman BC. (2002). Making sense of proprioception. Physiotherapy, 88, 667-76.

43. Surenkok O, Aytar A, Tuzun EH, Akman MN. (2008). Cryotherapy impairs knee joint position sense and balance. Isokinet Exerc Sci, 16, 69-73.

44. Thieme, H, Ingersoll, C, Knight, K and Ozmun, J. (1996). Cooling does not affect knee proprioception. J Athl Train, 31, 8-11.

45. Uchio Y, Ochi M, Fujihara A, Adichi N, Iwasa J, Sakai Y. (2003). Cryotherapy influences joint laxity and position sense of the healthy knee joint. Arch Phys Med Rehabil, 84, 131-135.

46. Vauhnik, R, Morrissey, M, Rutherford, O, Turk, Z, Pilih, I, and Pohar, M. (2008). Knee anterior laxity: a risk factor for traumatic knee injury among sports women? The Knee, 16, 823-833. 
47. Watanabe T, Terabayashi N, Shi B, Shin S, Kasuga K, Yabumoto T, Shimizu K, Matsuoka T. (2013). Effects of cryotherapy on joint position sense and intra-articular blood flow volume in healthy knee joints. J Phys Fit \& Sports Med, 2, 243-250.

48. Wassinger CA, Myers JB, Gatti JM, Conley KM, Lephart SM. (2007). Proprioception and throwing accuracy in the dominant shoulder after cryotherapy. J Athl Train, 42, 84-9.

49. Whatman C, Hume P, Hing W. (2013). Kinematics during lower extremity functional screening tests in young athletes - are they reliable and valid? Phys Ther Sport, 14, 87-93.

50. Williams G, Chmielewski T, Rudolph KS, et al. (2001). Dynamic knee stability: Current theory and implications for clinicians and scientists. J Orthop Sports Phys Ther, 31, 546-66.

51. World Medical Association. Declaration of Helsinki. 2008. http://www.wma.net/e/ethicsunit/helsinki.htm

52. Zazulak BT, Hewett TE, Reeves NP, Goldberg B, Cholewicki J. (2007). The effects of core proprioception on knee injury: a prospective biomechanical-epidemiological study. Am J Sports Med, 35, 368-373. 